\title{
Osteonecrosis of the lunate in systemic sclerosis-an underappreciated vascular complication?
}

\author{
Robert D. Sandler ${ }^{1} \cdot$ Adrian M. Highland $^{2} \cdot$ Michael Hughes $^{1}$ \\ Received: 10 March 2020 / Revised: 10 April 2020 / Accepted: 5 May 2020 / Published online: 16 May 2020 \\ (C) International League of Associations for Rheumatology (ILAR) 2020
}

A 71-year-old lady with known diffuse cutaneous SSc (antiscl-70 positive) reported non-inflammatory arthralgias in the small joints of the hands and wrists in keeping with osteoarthritis. Her disease (9-year history) was characterised by digital vasculopathy: Raynaud's phenomenon (10-year history) with previous digital ulcers and lung fibrosis/pulmonary hypertension. Current medication for SSc vasculopathy consisted of sildenafil and bosentan. Plain radiograph revealed established unilateral lunate osteonecrosis with secondary scapholunate advanced collapse (SLAC wrist), and evidence of generalised arthropathy, calcinosis and acro-osteolysis (Fig. 1a, b). Of note, the patient had also previously developed avascular necrosis of the head of the third metatarsal (Freiberg disease) (Fig. 1c).

Musculoskeletal hand symptoms are common in patients with SSc and often multi-factorial including (but not limited

Michael Hughes

Michael.hughes-6@postgrad.manchester.ac.uk

1 Department of Rheumatology, Sheffield Teaching Hospitals NHS Foundation Trust, Royal Hallamshire Hospital, Sheffield S10 2JF, UK

2 Department of Radiology, Sheffield Teaching Hospitals NHS Foundation Trust, Royal Hallamshire Hospital, Sheffield, UK to) arthritis (non-inflammatory and inflammatory), skin tightness and finger contractures [1]. Lunate osteonecrosis (also known as Kienböck's disease) has been reported in patients with SSc $[2,3]$. Patients can be asymptomatic or report wrist pain. Treatment is often conservative with careful watching and appropriate analgesia. Of mechanistic interest, an association between lunate osteonecrosis and severe Raynaud's phenomenon has been reported [2]. Selective ulnar artery vasculopathy is predicative of digital ulcers in SSc $[4,5]$. It has been hypothesised that ulnar artery involvement in SSc leads to compromised blood supply to the lunate resulting in avascular necrosis [2].

In conclusion, we present a case of lunate osteonecrosis which may be an underappreciated cause of wrist pain in patients with SSc and is a potential manifestation of SSc vasculopathy. 


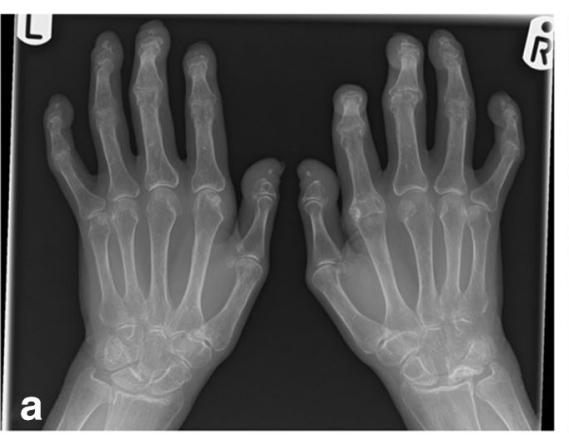

Fig. 1 Dorso-palmar radiographs of both hands showing acro-osteolysis of multiple terminal phalanges, and avascular necrosis of the right lunate with scapholunate dissociation (a). Dorso-palmar radiograph, right wrist showing a widened scapholunate interval, with flattening and sclerosis of

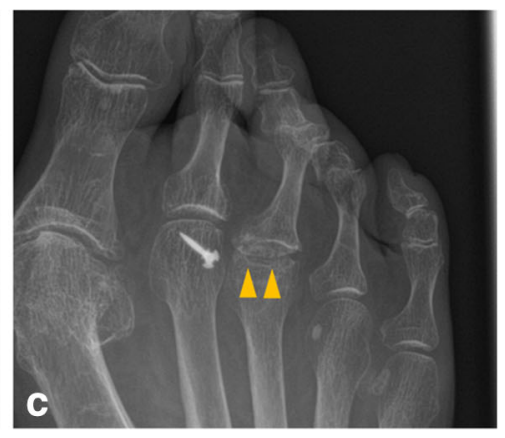

the lunate consistent with avascular necrosis (arrow heads) (b). Dorsoplantar radiograph of the right forefoot showing avascular necrosis of the head of the third metatarsal head (Freiberg disease) (c)

\section{Compliance with ethical standards}

Disclosures None.

\section{References}

1. Sandler RD, Matucci-Cerinic M, Hughes M (2020) Musculoskeletal hand involvement in systemic sclerosis. Semin Arthritis Rheum 50(2):329-334

2. Frerix M, Kröger K, Szalay G, Müller-Ladner U, Tarner IH (2016) Is osteonecrosis of the lunate bone an underestimated feature of

systemic sclerosis? A case series of nine patients and review of literature. Semin Arthritis Rheum 45(4):446-454

3. Bruni C, Guiducci S, Bellando-Randone S, Matucci-Cerinic M (2017 Aug) Avascular bone necrosis: an underestimated complication of systemic sclerosis. Semin Arthritis Rheum 47(1):e3-e5

4. Frerix M, Stegbauer J, Dragun D, Kreuter A, Weiner SM (2012) Ulnar artery occlusion is predictive of digital ulcers in SSc: a duplex sonography study. Rheumatology (Oxford) 51(4):735-742

5. Hughes M, Allanore Y, Chung L, Pauling JD, Denton CP, MatucciCerinic M (2020) Raynaud phenomenon and digital ulcers in systemic sclerosis. Nat Rev Rheumatol 16(4):208-221

Publisher's note Springer Nature remains neutral with regard to jurisdictional claims in published maps and institutional affiliations. 